\title{
Multi-period design of heat exchanger networks
}

\author{
Muhammad Imran Ahmad ${ }^{a, *}$, Nan Zhang ${ }^{b}$, Megan Jobson ${ }^{b}$, Lu Chen $^{c}$ \\ a Department of Chemical Engineering, University of Engineering and Technology, 25000, Peshawar, Pakistan \\ ${ }^{\mathrm{b}}$ Centre for Process Integration, School of Chemical Engineering and Analytical Science, The University of Manchester, PO Box 88 , \\ Sackuille Street, Manchester, M60 1QD, UK \\ c Process Integration Limited, One Central Park, Northampton Road, Manchester, M40 5BP, UK
}

\begin{abstract}
A B S T R A C T
Heat exchanger networks are an integral part of chemical processes as they recover available heat and reduce utility consumption, thereby improving the overall economics of an industrial plant. This paper focuses on heat exchanger network design for multi-period operation wherein the operating conditions of a process may vary with time. A typical example is the hydrotreating process in petroleum refineries where the operators increase reactor temperature to compensate for catalyst deactivation. Superstructure based multi-period models for heat exchanger network design have been proposed previously employing deterministic optimisation algorithms, e.g. (Aaltola, 2002; Verheyen and Zhang, 2006). Stochastic optimisation algorithms have also been applied for the design of flexible heat exchanger networks recently (Ma et al., 2007, 2008). The present work develops an optimisation approach using simulated annealing for design of heat exchanger networks for multi-period operation. A comparison of the new optimisation approach with previous deterministic optimisation based design approaches is presented to illustrate the utilisation of simulated annealing in design of optimal heat exchanger network configurations for multi-period operation.
\end{abstract}

( 2012 The Institution of Chemical Engineers. Published by Elsevier B.V. All rights reserved.

Keywords: Heat exchanger network; Multi-period; Simulated annealing; Design

\section{Introduction}

Heat exchanger networks are a means of utilising the heat available in a process by exchanging between hot and cold process streams, thereby decreasing energy demand and therefore utility costs, as well as capital investment in auxiliary equipment. Heat exchanger networks thus improve the economics of plant operation. Heat exchanger network design has long been the focus of research studies and remains an area of continuous development due to the current trend of increasing energy costs.

The operating conditions of a plant may vary with time. Firstly, unplanned and/or uncontrolled operational fluctuations in operating conditions around desired values or set points are inevitable. Secondly, planned periodic changes in operating conditions for enhancing performance is inherent to the nature of some processes. For example, the reactor operating temperature in processes such as hydrotreating and hydrocracking in refineries can be changed with time to compensate for catalyst deactivation; distillation column operating pressures can be varied to take advantage of seasonal variations in ambient temperatures. Heat exchanger networks that can remain operable in such varying operating conditions and optimal over the time period of interest are termed flexible heat exchanger networks. Flexible heat exchanger networks are classified as resilient or multi-period respectively, depending on the nature of variation in the plant operating conditions (Verheyen and Zhang, 2006). The aim of this work is to review and analyse multi-period heat exchanger network design and propose a new robust and effective approach using simulated annealing for optimisation.

\subsection{Review of design methodologies}

This section presents an overview of approaches for design of heat exchanger networks for fixed process operating conditions. A detailed discussion of these design methodologies can be found elsewhere (Nishida et al., 1981; Smith, 2005; Verheyen and Zhang, 2006). Since the pioneering work on

\footnotetext{
* Corresponding author. Tel.: +92 919218180.

E-mail address: Imran.Ahmad@nwfpuet.edu.pk (M.I. Ahmad).

Received 31 December 2010; Received in revised form 5 August 2011; Accepted 30 March 2012

0263-8762/\$ - see front matter @ 2012 The Institution of Chemical Engineers. Published by Elsevier B.V. All rights reserved. http://dx.doi.org/10.1016/j.cherd.2012.03.020
} 


\section{Nomenclature \\ A heat transfer area, $\mathrm{m}^{2}$ \\ AF annualisation factor \\ $A_{\max }$ maximum heat transfer area of a heat exchanger, $\mathrm{m}^{2}$ \\ B exponent for area cost \\ C area cost coefficient for heat exchangers, $€ /$ unit \\ $\mathrm{C}_{\mathrm{cu}} \quad$ per unit cost for cold utility, $€ /$ unit \\ $C_{\mathrm{f}} \quad$ fixed charge for heat exchanger unit, $€$ /unit \\ $\mathrm{C}_{\mathrm{hu}} \quad$ cost per energy unit for hot utility, $€ /$ unit \\ $\mathrm{CP}$ stream heat capacity flow rate, $\mathrm{kW} / \mathrm{K}$ \\ $C_{u t} \quad$ cost per energy unit cost for utility, $€ /$ unit \\ DOP duration of period \\ $\mathrm{F}_{\mathrm{T}} \quad$ logarithmic mean temperature difference cor- rection factor \\ $\mathrm{HU}_{\text {up }}$ upper bound on total hot utility available, kW \\ $\mathrm{N}_{\mathrm{CS}} \quad$ number of cold streams \\ $N_{E Q} \quad$ number of equations in the heat exchanger net- work model \\ $\mathrm{N}_{\mathrm{HS}} \quad$ number of hot streams \\ $N_{N D}$ number of nodes in the heat exchanger net- work \\ $N_{\mathrm{PHX}} \quad$ number of process heat exchangers \\ $N_{S P} \quad$ number of stream splitter-mixer units \\ $N_{\text {ST }} \quad$ number of process streams \\ $N_{\mathrm{TP}} \quad$ number of operating periods \\ $N_{U H X}$ number of utility heat exchangers \\ $\mathrm{N}_{\mathrm{UT}} \quad$ number of utilities \\ Q heat exchanger duty, $\mathrm{kW}$ \\ SF flow rate splitting fraction in a stream splitter \\ $\mathrm{T}$ temperature, ${ }^{\circ} \mathrm{C}$ \\ TC temperature of the cold stream in a heat exchanger, ${ }^{\circ} \mathrm{C}$ \\ TH temperature of the hot stream in a heat exchanger, ${ }^{\circ} \mathrm{C}$ \\ TMX temperature of a stream of a mixer, ${ }^{\circ} \mathrm{C}$ \\ TS supply temperature of a stream, ${ }^{\circ} \mathrm{C}$ \\ TSP temperature of a stream of a splitter, ${ }^{\circ} \mathrm{C}$ \\ $\mathrm{U}$ overall heat transfer coefficient, $\mathrm{kW} / \mathrm{m}^{2} \mathrm{~K}$ \\ $\mathrm{XBC} \quad$ fraction of cold stream bypassed \\ $\mathrm{XBH} \quad$ fraction of hot stream bypassed \\ $z \quad$ existence of process-to-process heat exchanger zut existence of utility heat exchanger}

\section{Abbreviations}

HEN heat exchanger network

LMTD logarithmic mean temperature difference

LP linear programming

MILP mixed integer linear programming

MINLP mixed integer nonlinear programming

NLP nonlinear programming

SA simulated annealing

TAC total annualised cost

$\begin{array}{ll}\text { Indices } & \\ \text { cs } & \text { cold stream of a heat exchanger } \\ \text { hs } & \text { hot stream of a heat exchanger } \\ i & \text { process heat exchanger } \\ j & \text { utility heat exchanger } \\ k & \text { heat exchanger } \\ l & \text { stream splitter }\end{array}$

\begin{tabular}{|ll|}
\hline$n$ & hot process stream \\
$n d$ & temperature node \\
$n d c$ & temperature node on a cold stream \\
$n d h$ & temperature node on a hot stream \\
0 & cold process stream \\
$p$ & period of operation \\
s & stage number or temperature interval \\
st & stream of a splitter \\
& \\
Sets & \\
CS & set of cold streams \\
HS & set of hot streams \\
HX & set of heat exchangers \\
PHX & set of process heat exchangers \\
SP & set of stream splitters \\
ST & set of streams \\
TP & set of operating periods \\
UHX & set of utility heat exchangers \\
UT & set of utility streams \\
\hline
\end{tabular}

heat exchanger network synthesis by Masso and Rudd (1969), based on heuristics, different strategies have been explored and developed. Heat exchanger network design methodologies have been classified based on the underlying approach; these are summarised here as background to the extension of conventional approaches to multi-period design.

\subsection{Pinch analysis and heat exchanger network design}

Pinch analysis is a thermodynamic tool for estimating minimum utility consumption, number of units and investment cost of a network for a given minimum approach temperature. Linnhoff and Hindmarsh (1983) proposed heuristic rules for heat exchanger network design based on the concept of the pinch temperature, i.e. the temperature where the net driving force for heat exchange is zero. This technique is developed using the systematic methods introduced by Hohmann (1971) and further refined by Linnhoff and Flower (1978).

Pinch analysis provides estimates for minimum energy and capital costs based on the material and energy balance of process streams. The design of a heat exchanger network is carried out by dividing the problem at pinch temperature. The network is designed above and below the pinch by starting at the pinch and moving away as there is more freedom in the choice of matches away from the pinch. The matches between hot and cold process streams and the heat exchanger duties are determined using heuristics to minimise the number of units and maximise the heat recovery (Smith, 2005).

\subsection{Sequential approaches for heat exchanger network design}

The sequential design approaches using the pinch theory decompose the heat exchanger network design problem into sub-problems for minimising utility costs, number of units and investment costs. The most widely employed models for estimating minimum utility consumption and number of units are the transshipment models of Papoulias and Grossmann (1983). The linear programming (LP) formulation of the transshipment model predicts minimum utility cost for a given system while a mixed integer linear programming (MILP) 
formulation develops heat exchanger network designs with the minimum number of heat exchangers. Alternative formulations based on the same concept have been developed, e.g. Cerda et al. (1983).

Floudas and Grossmann (1986) proposed a two-stage procedure using transshipment models to obtain the heat exchanger network configuration first with an MILP model and then the minimum total annualised cost using a non-linear programming (NLP) model. However, this decomposition of heat exchanger network design problem into sub-problems can lead to sub-optimal solutions. For example, heat exchanger networks with minimum total annualised costs but higher number of heat exchanger units are not considered in the search space. A later approach to sequential design of heat exchanger networks has been proposed by Zhu and co-workers (Zhu, 1995; Zhu et al., 1995; Zhu, 1997) where the problem is decomposed into enthalpy intervals.

\subsection{Simultaneous approaches for heat exchanger network design}

The simultaneous approaches make use of superstructures consisting of a variety of structural possibilities, and optimise them to remove redundant features. The trade-off between capital cost (fixed costs of heat exchanger units and area costs) and operating cost (hot and cold utility costs) is considered in a single rigorous optimisation framework in the simultaneous design approach for heat exchanger networks.

Floudas and Grossmann (1986) proposed one such superstructure consisting of a wide range of structural features. Ciric and Floudas (1991) presented a simultaneous approach for systematically determining optimal heat exchanger network designs by solving a single MINLP model. Yee et al. (1990) developed a simplified stage-wise superstructure with the assumption of isothermal mixing to simplify the formulation. Yee and Grossmann (1991) proposed an MINLP model based on this simplified stage-wise superstructure. Bjork and Westerlund (2002) proposed a methodology based on the same simplified stage-wise superstructure but without the assumption of isothermal mixing. The main drawback of the simultaneous heat exchanger network design approaches is the difficulty in solving these large size models.

\subsection{Stochastic optimisation methods for heat exchanger network design}

Stochastic optimisation methods address both structural and parametric variables simultaneously and do not rely on decomposition of the design problem into smaller subproblems. Some commonly used stochastic optimisation methods for process design are simulated annealing, genetic algorithm and Tabu search method (Verheyen, 2005). Simulated annealing has been successfully applied for synthesis and optimisation of heat exchanger networks (Dolan et al., 1990; Nielsen et al., 1994; Athier et al., 1996, 1997; Rodriguez, 2005; Chen, 2008). Genetic algorithms based on the analogy with the process of natural evolution, have been applied for heat exchanger network design and optimisation (Androulakis and Venkatasubramanian, 1991; Lewin, 1998; Lewin et al., 1998; Ravagnani et al., 2005). Tabu search is an iterative improvement method for optimisation with a characteristic feature of short-term memory to keep track of previously found solutions. Tabu search has been applied to heat exchanger network design (Lin and Miller, 2004). Some other hybrid strategies (Yu, 2000) have also been applied for optimisation of heat exchanger networks.

\subsection{Critical analysis of heat exchanger network design methodologies}

Pinch analysis has been widely applied in targeting stage of process design, i.e. estimation of minimum hot and cold utility demand for a given system. Pinch analysis is also applied for screening of various design options. However, it can be misleading in some cases, as pinch analysis does not take into account heat transfer coefficients thoroughly (Verheyen and Zhang, 2006). Sequential approaches decompose the problem into easy-to-solve sub problems. This decomposition into sub-problems with different objectives may fail to account for trade-offs between capital and operating costs. Simultaneous approaches offer promising results in comparison to the sequential approaches. However, the problem size, complexity and issues associated with local optima are drawbacks. Stochastic optimisation methods allow a thorough search of the solution space in order to obtain near optimal solutions, at the expense of computational time (Dolan et al., 1990).

\section{Multi-period heat exchanger network design}

A multi-period heat exchanger network is a heat exchanger network that would be operated in a series of different set of conditions, such as temperatures and heat loads. It should remain feasible, i.e. provide the heating and cooling requirements of the process streams, under these different operating modes and its design should be optimal in terms of the overall costs. The operating conditions of a heat exchanger network may vary with process changes, such as feedstock, throughput and operating conditions, as a result the network of heat exchangers must satisfy different heat loads in different operating periods. Its design may include bypasses; furthermore, as the optimal solution may represent more than one value of required heat exchanger area for a given match in different operating periods, the maximum area out of these values must be considered for cost calculations. The design strategies introduced in the previous section are all based on fixed values of stream temperatures and heat capacity flow rates and therefore, cannot be employed directly for the design of flexible heat exchanger networks.

In multi-period design it is assumed that specified values of flow rates, temperatures and heat capacities are available for the different operating periods under consideration. The aim of multi-period design is to obtain a heat exchanger network that can satisfy the heating and cooling requirements of all the operating periods while minimising its total annualised cost, i.e. utility costs and annualised heat exchanger capital costs.

\subsection{Sequential approach for multi-period heat exchanger network design}

Floudas and Grossmann (1986) proposed a sequential approach to address multi-period design of heat exchanger networks based on the transshipment models of Papoulias and Grossmann (1983). The approach employs the LP transshipment model to estimate the minimum utility consumption for each operating period, and then a multi-period 
formulation of the MILP transshipment model is used to obtain a configuration that has the fewest heat exchanger units and incurs the minimum utility cost for each period. The drawback of this approach is that heat exchanger network configurations with higher number of heat exchanger units but lower total annualised costs are neglected. A more recent approach to sequential design of flexible heat exchanger networks has been proposed by Tantimuratha et al. (2001). However, this methodology may also lead to sub-optimal solutions as it relies on decomposition (Verheyen and Zhang, 2006).

Sequential approaches have also been proposed previously for the design of resilient heat exchanger networks. For example, Swaney and Grossmann (1985a,b) proposed flexibility index to account for the ability of a design to remain feasible for variation in operating parameters around nominal operating conditions. Cerda and co-workers proposed sequential approach for the design of flexible heat exchanger networks with minimum utility consumption taking into account uncertainty in temperatures and flow rates of process streams (Cerda et al., 1990; Cerda and Galli, 1990; Galli and Cerda, 1991). However, design of resilient heat exchanger networks is not discussed in detail here as this paper focuses on design of multi-period heat exchanger networks.

\subsection{Simultaneous approach for multi-period heat exchanger network design}

The simultaneous approaches for multi-period heat exchanger network design formulate the optimisation problem of heat exchanger network design by introducing variables such as the duties of all process-to-process and utility heat exchangers, flow rates and temperatures of streams for all the periods of operation under consideration. The binary variables representing the existence of both processto-process and utility heat exchangers are independent of the operating periods (Aaltola, 2002).

The constraints for the multi-period HEN design problem are as follows:

- Overall heat balances for streams hold in each operating period

- Stage-wise heat balances for streams hold in each operating period

- The assignment and feasibility of stream temperatures, at each stage in all the operating periods, based on the inlet and outlet stream temperatures

- Logical constraints for existence of matches between streams.

Aaltola (2002) proposed a multi-period simultaneous approach to minimise the overall costs using an extension of the simplified stage-wise superstructure of Yee et al. (1990). A simplified illustration of this superstructure incorporating two hot streams and two cold streams is shown in Fig. 1.

As can be seen in Fig. 1, for a system with two hot streams and two cold streams the superstructure consists of four heat exchangers per stage for a given operating period.

The multi-period optimisation model proposed by Aaltola (2002) is based on the MINLP formulation of Yee and Grossmann (1991). The MINLP model optimises the heat exchanger network structure with the assumption of isothermal mixing, i.e. streams can only be mixed if they are at the same temperature. A multi-period NLP formulation in the second stage then adjusts the flow rates and duties of

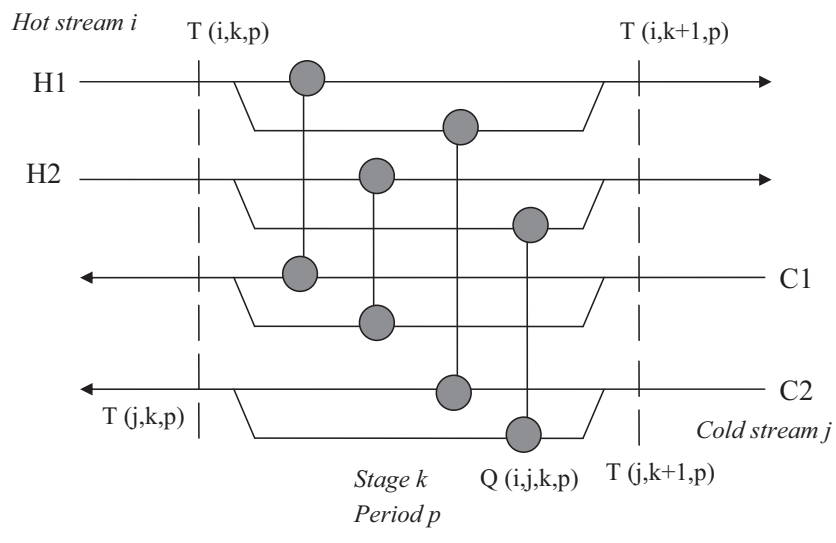

Fig. 1 - A simplified version of multi-period extension of the stage-wise superstructure (Verheyen and Zhang, 2006).

exchangers to improve the total annualised cost of the network.

The objective function of Aaltola (2002), i.e. the total annualised cost, is the sum of unit costs of all heat exchangers, mean area costs of all process and utility matches and mean hot utility costs and cold utility costs. The assumption of mean area costs in the MINLP model can lead to sub-optimal solutions (Verheyen and Zhang, 2006). Verheyen and Zhang (2006) modified this simultaneous approach for multi-period heat exchanger network design to account for the maximum area costs in the objective function.

Ma and co-workers (Ma et al., 2007, 2008) proposed a simultaneous two-stage strategy employing stochastic optimisation techniques such as genetic algorithm and simulated annealing for synthesis of flexible multi-stream heat exchanger networks. First, a pseudo-temperature enthalphy (T-H) diagram method is employed to obtain a suitable HEN configuration. Stochastic optimisation is adopted in the second stage for optimisation of heat exchanger areas.

\subsection{Limitations of previous multi-period heat exchanger network design methodologies}

The sequential approach proposed by Floudas and Grossmann (1986) has the inherent weakness of not taking into account the trade-offs between area, number of heat exchanger units, and energy costs rigorously, although the decomposition of the problem into stages helps reduce the size of the problem (Verheyen and Zhang, 2006). The simultaneous approaches of Aaltola (2002) and Verheyen and Zhang (2006) have addressed this issue but make use of a simplified superstructure, to keep the problem size manageable without decomposition. However, the simplified stage-wise superstructure excludes some structural features of heat exchanger network configurations. For example, it does not include splitting streams with two or more heat exchangers in series on one branch, stream bypassing or any structural combination of these two features.

\section{Proposed methodology for multi-period HEN design using simulated annealing}

Simulated annealing is a multivariable combinatorial optimisation technique (Kirkpatrick et al., 1983), based on the Monte Carlo algorithm. Simulated annealing algorithm searches for the optimal solution of an optimisation problem based on the evaluation of objective function at randomly selected points within the search space. Simulated annealing has been 


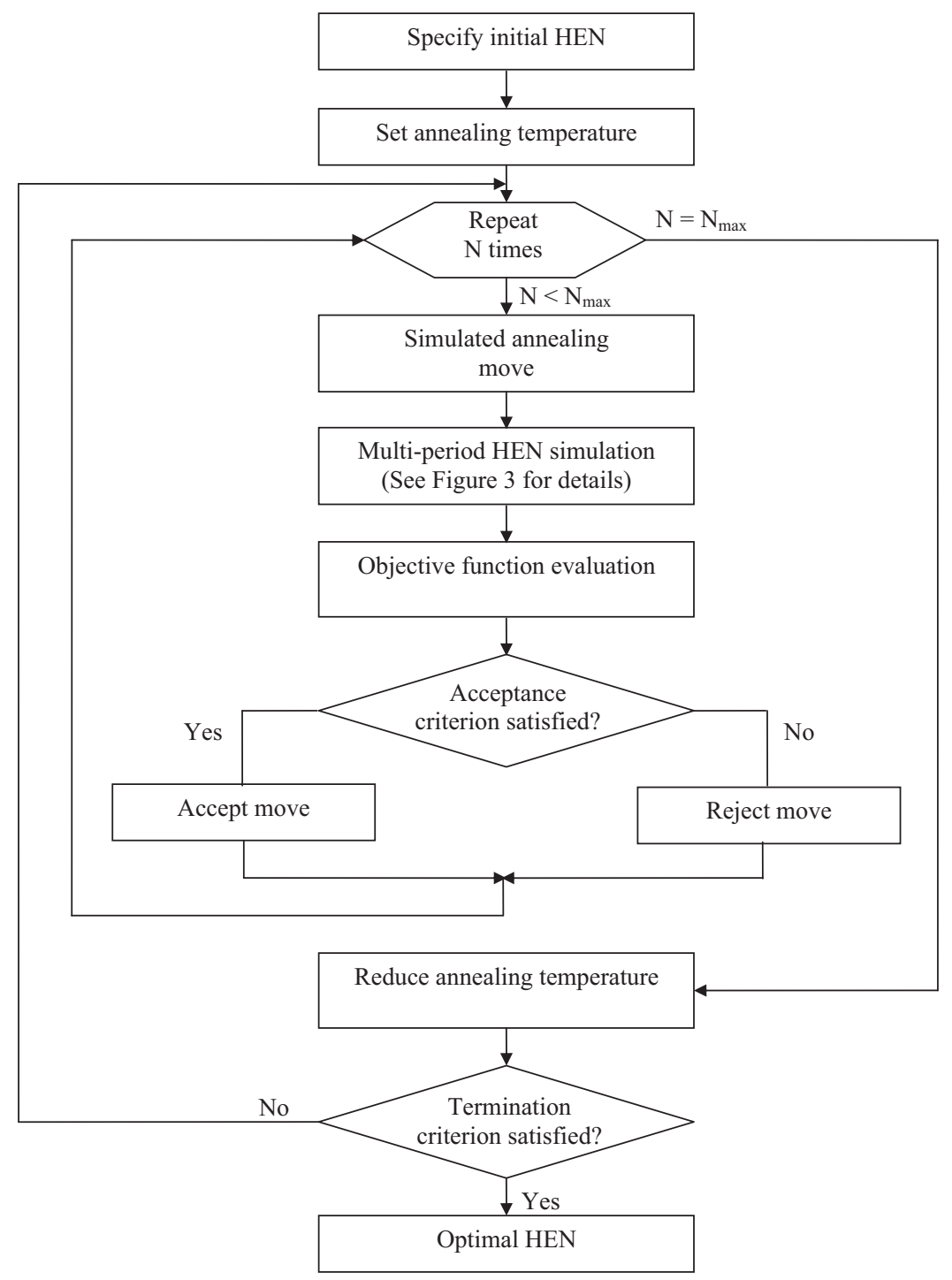

Fig. 2 - Simulated annealing algorithm for multi-period heat exchanger network design.

successfully applied for synthesis and optimisation of heat exchanger networks (Dolan et al., 1990; Nielsen et al., 1994; Athier et al., 1996, 1997; Rodriguez, 2005; Chen, 2008). The heat exchanger network structures generated by simulated annealing can involve stream splitting, mixing, bypass and multiple matches between same pairs of streams. A multi-period heat exchanger network design methodology employing simulated annealing algorithm for the search of flexible network configurations, and capital-energy optimisation is presented in this Section.

\subsection{Simulated annealing for multi-period heat exchanger network design}

The application of simulated annealing for multi-period heat exchanger network design requires an understanding of multi-period operation and of the characteristic features of multi-period heat exchanger networks. For example, the maximum area consideration for heat exchangers based on all the operating periods of interest, i.e. a given heat exchanger may have to satisfy different heat loads and thus the required heat transfer area may be different in different operating periods; however, the cost calculation would need to be based on the maximum area amongst these values. Fig. 2 shows the algorithm for multi-period design of heat exchanger networks with simulated annealing.

The proposed methodology employs simulated annealing to search for optimal heat exchanger network configurations starting from a feasible initial heat exchanger network, and an appropriate high value of the annealing temperature. A feasible heat exchanger network is one that can satisfy the heating and cooling requirements of a given system and also satisfies the minimum approach temperature constraint for each heat exchanger unit. A very simple and convenient initial guess for a feasible heat exchanger network is to match all the hot process streams with a cold utility and the cold process streams with a hot utility.

The simulated annealing algorithm modifies this initial heat exchanger network configuration by making random changes known as random moves. Table 1 presents a list of possible simulated annealing moves for modifications to a heat exchanger network. The modifications made to the existing network configuration as shown in Table 1 are classified into two categories based on the nature of the variables involved. The continuous moves result in changes in duties of heat exchangers or flow fractions in various branches of a stream, while structural moves involve manipulation of binary variables and result in changes in heat exchanger network configuration. 


Table $\mathbf{1}$ - Simulated annealing moves for heat exchanger
network design.

The modified structure is then simulated for multiple periods of operation. The simulation of a heat exchanger network for multi-period operation is explained in the next section. The objective function is evaluated, i.e. the objective function value for current configuration is compared to that of the previous configuration, and the modification may be accepted or rejected based on the acceptance criterion employed. The Metropolis acceptance criterion (Metropolis et al., 1953) has been used throughout this work. This process is repeated a number of times $(\mathrm{N})$ to obtain a set of sample solutions, as governed by the Markov chain length $\left(\mathrm{N}_{\max }\right)$, and the annealing temperature is progressively reduced. In this way, the simulated annealing algorithm searches for the optimal heat exchanger network configuration for multi-period design. Once the termination criterion is satisfied, i.e. the specified lower limit of the annealing temperature is reached, the best design obtained so far is reported as the optimal multi-period heat exchanger network.

\subsection{Multi-period heat exchanger network simulation model}

In the methodology proposed in this work, for multi-period heat exchanger network design using the simulated annealing algorithm, any modifications made to the heat exchanger network need to be simulated for all the operating periods under consideration. The multi-period simulation of heat exchanger network structure modified by the algorithm is shown in Fig. 3. The heating and cooling requirements of the process streams may vary from one operating period to another, as a result the matches proposed by the simulated annealing algorithm may

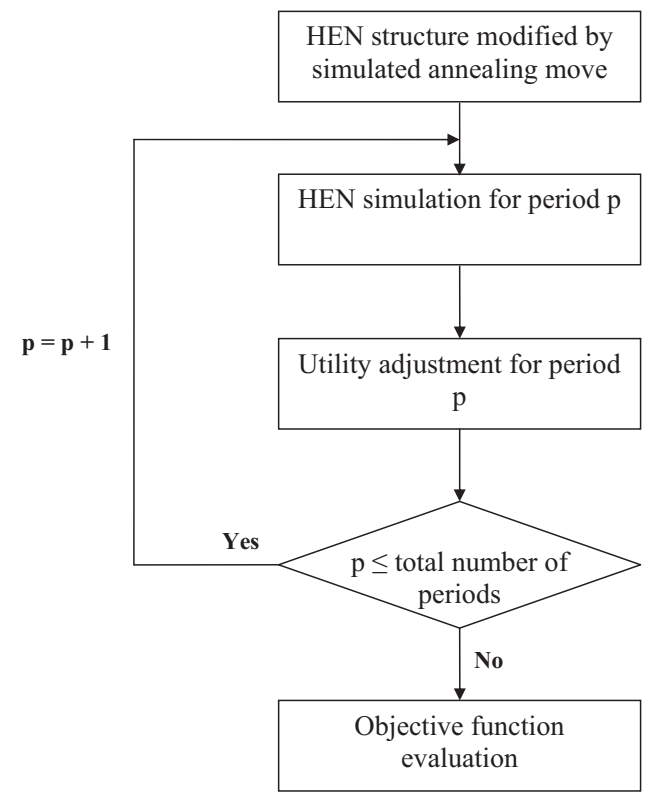

Fig. 3 - Multi-period simulation of heat exchanger network.

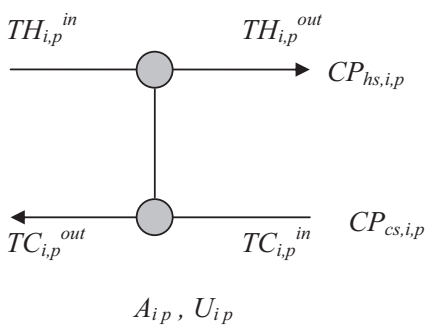

Fig. 4 - A single heat exchanger for multi-period operation.

not satisfy the constraints of outlet temperatures of the hot and cold process streams in some operating periods. Therefore, the hot and/or cold utility load is adjusted for each operating period. Once the modified structure has been simulated for all the operating periods under consideration and the corresponding utilities have been adjusted, the objective function can be evaluated by comparison with the previous best solution.

The multi-period model developed in this work is based on the heat exchanger network simulation model proposed by Rodriguez (2005), and is modified to account for periodic changes in operating parameters of process streams. The heat exchanger network model for multi-period operation is based on the following assumptions:

- Mass flow rates of process streams are assumed to remain constant in each operating period.

- The physical properties of fluid streams such as the heat capacities are assumed to be constant and independent of temperature in each operating period.

- Heat transfer coefficients are assumed to be constant throughout each heat exchanger.

\subsubsection{Process heat exchangers}

This work focuses on the design of heat exchanger networks, where we need to calculate the heat exchanger area required for a given heat load. Thus for a heat exchanger, $i \in P H X$ in a given operating period $p \in \mathrm{TP}$ as shown in Fig. 4, heat is transferred from the hot stream $h s_{i} \in H S$, to the cold stream $c s_{i} \in C S$.

The temperature of the hot stream decreases from $\mathrm{TH}_{i}{ }^{\text {in }}$ to $\mathrm{TH}_{i}{ }^{\text {out }}$, while the temperature of the cold stream increases from $\mathrm{TC}_{i}{ }^{\text {in }}$ to $\mathrm{TC}_{i}$ out . The thermal duty or heat load of the heat exchanger, i.e. the heat transferred between the two streams is a function of the inlet temperatures of the streams and their heat capacity flow rates. This heat load is given by Eqs. (1) and (2):

$\mathrm{Q}_{i, p}=C P_{h s_{i, p}}\left(\mathrm{TH}_{i, p}^{\mathrm{in}}-\mathrm{TH}_{i, p}^{\text {out }}\right)$

$\mathrm{Q}_{i, p}=\mathrm{CP}_{\mathrm{cs} i, p}\left(\mathrm{TC}_{\mathrm{i}, p}^{\mathrm{out}}-\mathrm{TC}_{i, p}^{\mathrm{in}}\right)$

The outlet temperature of the hot and cold stream can be calculated using Eqs. (3) and (4):

$\mathrm{TH}_{i, p}^{\text {out }}=\mathrm{TH}_{i, p}^{\text {in }}-\frac{\mathrm{Q}_{i, p}}{\mathrm{CP}_{\mathrm{hs}_{i, p}}}$

$\mathrm{TC}_{i, p}^{\text {out }}=\mathrm{TC}_{i, p}^{\text {in }}+\frac{\mathrm{Q}_{i, p}}{\mathrm{CP}_{\mathrm{cs}_{i, p}}}$ 


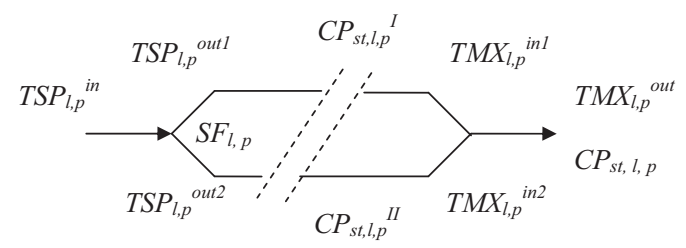

Fig. 5 - A splitter-mixer unit for multi-period heat exchanger network.

The area of the heat exchanger is calculated using Eq. (5):

$A_{i, p}=\frac{Q_{i, p}}{U_{i, p} \times F_{T_{i, p}} \times L_{M T D}, p}$

where

$\operatorname{LMTD}_{i, p}=\frac{\left(\mathrm{TH}_{i, p}^{\text {in }}-\mathrm{TC}_{i, p}^{\text {out }}\right)-\left(\mathrm{TH}_{i, p}^{\text {out }}-\mathrm{TC}_{i, p}^{\text {in }}\right)}{\ln \left(\mathrm{TH}_{i, p}^{\text {in }}-\mathrm{TC}_{i, p}^{\text {out }} / \mathrm{TH}_{i, p}^{\text {out }}-\mathrm{TC}_{i, p}^{\text {in }}\right)}$

The correction factor $F_{T}$ depends on the type of heat exchanger used and can be calculated, for example, using the correlations presented by Smith (2005).

\subsubsection{Utility heat exchangers}

The heating and cooling duties of process streams that cannot be satisfied by process-to-process heat exchange are supplied by utility heat exchangers. The utility heat exchangers are specified in terms of the heat load and are modelled similarly to the process heat exchangers, except that only the process side of the utility heat exchangers is considered explicitly. For a heater:

$\mathrm{T}_{j, p}^{\text {out }}=\mathrm{T}_{j, p}^{\text {in }}+\frac{\mathrm{Q}_{j, p}}{\mathrm{CP}_{\mathrm{cs}} \mathrm{s}_{j, p}}$

For a cooler:

$\mathrm{T}_{j, p}^{\text {out }}=\mathrm{T}_{j, p}^{\text {in }}-\frac{\mathrm{Q}_{j, p}}{\mathrm{CP}_{h s_{j, p}}}$

The area of utility heat exchangers is calculated using the same equation as for process heat exchangers and the log mean temperature difference is given by Eq. (9):

$\operatorname{LMTD}_{j, p}=\frac{\left(\mathrm{T}_{j, p}^{\text {in }}-\mathrm{TU}_{j, p}^{\text {out }}\right)-\left(\mathrm{T}_{j, p}^{\text {out }}-\mathrm{TU}_{j, p}^{\text {in }}\right)}{\ln \left(\mathrm{T}_{j, p}^{\text {in }}-\mathrm{TU}_{j, p}^{\text {out }} / \mathrm{T}_{j, p}^{\text {out }}-\mathrm{TU}_{j, p}^{\text {in }}\right)}$

Where $T U^{\text {in }}{ }_{j}, p$ and $T U^{\text {out }}{ }_{j}, p$ are the inlet and outlet temperatures of the utility stream in operating period $p$.

\subsubsection{Stream splitters and mixers}

Stream splitting provides flexibility to heat exchanger networks by better utilisation of the temperature driving forces in heat exchangers and thus helps in reducing the required heat transfer area. The model assumes that each splitter has only two branches and all the branches of a stream are remixed before leaving the heat exchanger network. Therefore, each splitter is associated with a mixer. Streams with more than two branches can be modelled by nesting splitters one inside the other. Fig. 5 shows a splitter-mixer unit, $l \in S P$ in a given operating period $p \in \mathrm{TP}$, which splits a stream, st $\in \mathrm{ST}$ into two branches.
The branch flow rates depend on the split fraction and the flow rate of the inlet stream. The heat capacity flow rates of the branch streams are given by Eqs. (10) and (11):

$$
\begin{aligned}
& \mathrm{CP}_{\mathrm{st} l, p}^{\mathrm{I}}=\mathrm{SF}_{l, p} \times \mathrm{CP}_{\mathrm{st} \mathrm{t}_{l, p}} \\
& \mathrm{CP}_{\mathrm{st} l, p}^{\mathrm{II}}=\left(1-\mathrm{SF}_{l, p}\right) \times \mathrm{CP}_{\mathrm{st} \mathrm{t}_{l, p}}
\end{aligned}
$$

The temperatures of the branch streams are the same as the temperature of the inlet stream given by Eqs. (12) and (13):

$$
\begin{aligned}
& \operatorname{TSP}_{l, p}^{\text {out1 }}=\operatorname{TSP}_{l, p}^{\text {in }} \\
& \operatorname{TSP}_{l, p}^{\text {out2 }}=\operatorname{TSP}_{l, p}^{\text {in }}
\end{aligned}
$$

The temperature of the mixer outlet stream is obtained by carrying out energy balance over the mixing point and is given by Eq. (14):

$\mathrm{TMX}_{l, p}^{\text {out }}=\frac{\mathrm{TMX}_{l, p}^{\mathrm{in} 1} \times \mathrm{CP}_{s t_{l, p}^{I}}^{\mathrm{I}}+\mathrm{TMX}_{l, p}^{\mathrm{in} 2} \times C P_{s t_{l, p}}^{\mathrm{II}}}{C P_{s t_{l, p}}}$

\subsubsection{Stream bypassing}

Stream bypassing involves re-routing of a fraction of a stream upstream of the inlet to a heat exchanger to be mixed again at the outlet. Stream bypassing provides a degree of freedom to manipulate heat loads and stream temperatures. Heat exchangers with bypass streams are modelled using Eqs. (15) and (16):

$$
\begin{aligned}
& \mathrm{TH}_{i, p}^{\text {out2 }}=\mathrm{TH}_{i, p}^{\text {in }}-\frac{\mathrm{Q}_{i, p}\left(1-\mathrm{XBH}_{i, p}\right)}{C P_{h s_{i, p}}} \\
& \mathrm{TC}_{i, p}^{\text {out2 }}=\mathrm{TC}_{i, p}^{\text {in }}+\frac{\mathrm{Q}_{i, p}\left(1-\mathrm{XBC} C_{i, p}\right)}{\mathrm{CP}_{\mathrm{Cs} s_{i, p}}}
\end{aligned}
$$

Where $\mathrm{XBH}_{i}, p$ and $\mathrm{XBC} C_{i}, p$ represent the fraction of the stream bypassed from a heat exchanger in a particular operating period. The variables $\mathrm{TH}_{i, p}$ out2 and $\mathrm{TC}_{i, p}$ out2 represent the temperatures of the hot and cold streams after the bypassed stream is re-mixed with the heat exchanger outlet stream.

\subsubsection{Simulation of the overall heat exchanger network}

The modelling equations presented in the previous sections describe the behaviour of individual units. However, the performance of the overall heat exchanger network depends on the connections and interactions between these components and can only be simulated by combining the individual component models and solving them simultaneously.

The individual network components such as heat exchangers, and splitter-mixer units, are connected to each other by specifying nodes on each stream of the heat exchanger network. Fig. 6 shows a heat exchanger network, its network components, and nodes on each stream. The location of any network component is identified by its inlet, $n d^{\text {in }}$ and outlet node $n d^{\text {out }}$. For example, the location of heat exchanger E2 in Fig. 6 is represented by the inlet and outlet nodes of its hot side, $n d h_{E 2}^{\text {in }}=3$ and $n d h_{E 2}^{\text {out }}=4$, and the inlet and outlet nodes of its cold side, $n d c_{E 2}^{i n}=10$ and $n d c_{E 2}^{\text {out }}=11$.

The representation of a heat exchanger network in terms of temperature nodes requires that each node is associated with a unique temperature and that the temperatures of the network components sharing a common node are same. The 


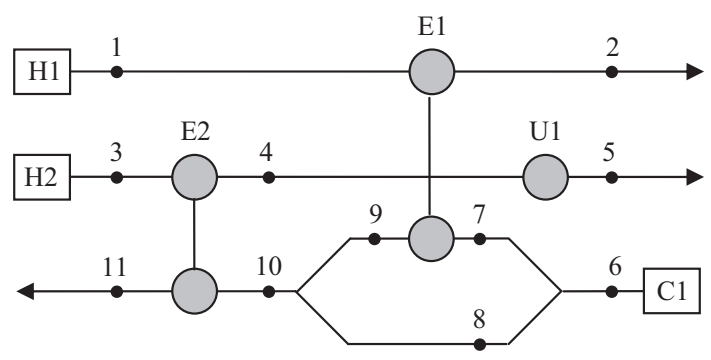

Fig. 6 - Representation of a heat exchanger network based on temperature nodes.

total number of temperature nodes required for simulation of a heat exchanger network operating in multiple periods is given by Eq. (17):

$\mathrm{N}_{\mathrm{ND}, p}=\mathrm{N}_{\mathrm{ST}, p}+2 \mathrm{~N}_{\mathrm{PHX}, p}+\mathrm{N}_{\mathrm{UHX}, p}+3 \mathrm{~N}_{\mathrm{SP}, p}$

Where $N_{\mathrm{ST}, p}$ is the number of streams, $N_{\mathrm{PHX}, p}$ the number of process heat exchangers, $N_{U H X, p}$ the number of utility heat exchangers and $N_{S P, p}$ the number of splitter-mixer units operating in a given period of operation.

The total number of equations, in the multi-period heat exchanger network model, is given by Eq. (18):

$\mathrm{N}_{\mathrm{EQ}, p}=\mathrm{N}_{\mathrm{ST}, p}+2 \mathrm{~N}_{\mathrm{PHX}, p}+\mathrm{N}_{\mathrm{UHX}, p}+3 \mathrm{~N}_{\mathrm{SP}, p}$

It can be observed here that the number of equations is equal to the number of variables and hence we can simulate the network by solving the equations simultaneously. The heat exchanger network shown in Fig. 6 can be represented by the equations given in Table 2 . This heat exchanger network consists of three process streams, two process heat exchangers, one utility heat exchanger and one splitter-mixer unit. It can be seen that there are eleven unknown node temperatures, for each operating period, which can be calculated by solving the same number of equations of the model.

\subsection{Objective function for multi-period heat exchanger network design}

The objective function for the optimisation is the total annualised cost of the multi-period heat exchanger network. The total annualised cost for multi-period design is the sum of all annualised capital costs (heat exchanger unit costs and maximum area costs based on the consideration of multiple periods of operation) and operating costs (hot and cold utility costs). The hot and cold utility costs are calculated as the

\section{Table 2 - Multi-period simulation model for the heat} exchanger network shown in Fig. 6.

Exchangers E1 and E2:

$\mathrm{T}_{2, p}=\mathrm{T}_{1, p}-\mathrm{Q}_{E 1, p} / C P_{H 1, p}$

$\mathrm{T}_{9, p}=\mathrm{T}_{7, p}+\mathrm{Q}_{E 1, p} / C P_{C 1, p}^{I}$

$\mathrm{T}_{4, p}=\mathrm{T}_{3, p}-\mathrm{Q}_{E 2, p} / \mathrm{CP}_{\mathrm{H} 2, p}$

$\mathrm{T}_{11, p}=\mathrm{T}_{10, p}+\mathrm{Q}_{\mathrm{E} 2, p} / \mathrm{CP}_{\mathrm{C} 1, p}$

Utility heat exchanger U1:

Splitter-mixer unit:

Temperature

specifications:
$\mathrm{T}_{5, p}=\mathrm{T}_{4, p}-\mathrm{QU}_{1, p} / \mathrm{CP}_{\mathrm{H} 2, p}$

$\mathrm{T}_{7, p}=\mathrm{T}_{6, p}$

$\mathrm{T}_{8, p}=\mathrm{T}_{6, p}$

$\mathrm{T}_{10, p}=\frac{\mathrm{T}_{9, p} \times \mathrm{CP}_{\mathrm{C} 1, p}^{\mathrm{I}}+\mathrm{T}_{8, p} \times \mathrm{CP}_{\mathrm{C} 1, p}^{\mathrm{II}}}{{ }^{\mathrm{CP}}{ }_{\mathrm{C} 1, p}}$

$\mathrm{T}_{1, p}=\mathrm{TS}_{\mathrm{H} 1, p}$

$\mathrm{T}_{3, p}=\mathrm{TS}_{\mathrm{H} 2, p}$

$\mathrm{T}_{6, p}=\mathrm{TS}_{\mathrm{C} 1, p}$
Table 3 - Process streams considered in the design of heat exchanger network for vacuum gas oil hydrotreater unit of an oil refinery.

\begin{tabular}{ll} 
Stream name & Description of stream in flow sheet \\
\hline H1 & Reactor outlet stream \\
H2 & $\begin{array}{l}\text { Diesel stream from distillation side } \\
\text { stripper }\end{array}$ \\
H3 & Gas oil stream from reboiler \\
C1 & Reactor inlet stream \\
C2 & Stream from low pressure separator to \\
C3 & $\mathrm{H}_{2} \mathrm{~S}$ stripper \\
C4 & Stream from $\mathrm{H}_{2} \mathrm{~S}$ stripper to distillation \\
& inlet \\
& Side stripper reboiler \\
\hline
\end{tabular}

weighted sum of these costs for all the operating periods under consideration.

The objective function for multi-period heat exchanger network design is given by Eq. (19):

$$
\begin{aligned}
& \min T A C=A F \cdot\left[\sum_{i \in P H X} C_{f} \cdot z_{i}+\sum_{j \in U X H} C_{f} \cdot z u t_{j}\right]+A F \cdot \sum_{i \in P H X} C \cdot A \max _{i}^{B} \\
& +\mathrm{AF} \cdot \sum_{j \in U H X} C \cdot A \max _{U t_{j}}^{B}+\sum_{p \in T P} \frac{D_{P} P_{p}}{N_{T P}} \cdot \sum_{j \in U H X} C_{u t} \cdot Q_{U t j, p}
\end{aligned}
$$

Where Amax refers to the maximum area of heat transfer required for any heat exchanger from all the operating periods under consideration.

\section{Case study}

In this section a case study is presented to allow a comparison of the new optimisation approach using simulated annealing, for multi-period heat exchanger network design, with existing deterministic methods. The MINLP-NLP model of Verheyen and Zhang (2006) is chosen as benchmark for comparison as the annual network cost obtained from their model has been demonstrated to be lower than the average annual network cost obtained by the previous models developed by Yee et al. (1990), and Aaltola (2002) (Verheyen and Zhang, 2006).

This case study has been taken from Verheyen and Zhang (2006). The objective of the case study is to design a heat exchanger network for the vacuum gas oil hydrotreater unit of an oil refinery. Vacuum gas oil hydrotreating process is a heavy hydrocarbon conversion process for upgrading vacuum gas oil to gas oil, diesel, gasoline and light products. The heat exchanger network should remain feasible, i.e. satisfy the heating and cooling requirements of all process streams, for all the specified operating periods. The objective is to minimise the total annualised cost given by Eq. (19). The three operating periods under consideration correspond to different process conditions resulting from catalyst deactivation in the reactor:

- Start-of-run

- Middle-of-run

- End-of-run

The process streams to be considered for heat recovery are presented in Table 3. 
Table 4 - Stream data for the first operating period, i.e. start-of-run condition.

\begin{tabular}{llll} 
Stream & $\begin{array}{l}\text { Inlet } \\
\text { temperature } \\
\left({ }^{\circ} \mathrm{C}\right)\end{array}$ & $\begin{array}{l}\text { Outlet } \\
\text { temperature } \\
\left({ }^{\circ} \mathrm{C}\right)\end{array}$ & $\begin{array}{l}\text { Heat capacity } \\
\text { flow rate } \\
(\mathrm{kW} / \mathrm{K})\end{array}$ \\
\hline $\mathrm{H} 1$ & 393 & 60 & 201.6 \\
$\mathrm{H} 2$ & 160 & 40 & 185.1 \\
$\mathrm{H} 3$ & 354 & 60 & 137.4 \\
$\mathrm{C} 1$ & 72 & 356 & 209.4 \\
$\mathrm{C} 2$ & 62 & 210 & 141.6 \\
$\mathrm{C} 3$ & 220 & 370 & 176.4 \\
$\mathrm{C} 4$ & 253 & 284 & 294.4 \\
\hline
\end{tabular}

Table 5 - Stream data for second operating period, i.e. middle-of-run condition.

\begin{tabular}{llll} 
Stream & $\begin{array}{l}\text { Inlet } \\
\text { temperature } \\
\left({ }^{\circ} \mathrm{C}\right)\end{array}$ & $\begin{array}{l}\text { Outlet } \\
\text { temperature } \\
\left({ }^{\circ} \mathrm{C}\right)\end{array}$ & $\begin{array}{l}\text { Heat capacity } \\
\text { flow rate } \\
(\mathrm{kW} / \mathrm{K})\end{array}$ \\
\hline $\mathrm{H} 1$ & 406 & 60 & 205.0 \\
$\mathrm{H} 2$ & 160 & 40 & 198.8 \\
$\mathrm{H} 3$ & 362 & 60 & 136.4 \\
$\mathrm{C} 1$ & 72 & 365 & 210.3 \\
$\mathrm{C} 2$ & 62 & 210 & 141.0 \\
$\mathrm{C} 3$ & 220 & 370 & 175.4 \\
$\mathrm{C} 4$ & 250 & 290 & 318.7 \\
\hline
\end{tabular}

Tables 4-6 provide the stream data for each of the three operating periods. All the three operating periods are assumed to have equal durations.

Heat exchanger costs are evaluated using the formula:

Heat exchanger cost $=C_{f}+C .(\text { Area })^{B}$

where $C_{f}$ is the fixed cost of a heat exchanger $=8333.3 €$. $C$ is the area cost coefficient for a heat exchanger $=641.7 € / \mathrm{m}^{2} . B$ is the area exponent $=1$. Annualisation factor used $=0.2$.

The overall heat transfer co-efficient used for the calculation of heat exchanger areas is $0.1 \mathrm{~kW} / \mathrm{m}^{2} \mathrm{~K}$ (Verheyen, 2005; Verheyen and Zhang, 2006). Economic data for energy costs are also taken from Verheyen (2005) and are as follows: $C_{\mathrm{cu}}$ is the cost of cold utility $\left(0-10^{\circ} \mathrm{C}\right)=1.3 € / \mathrm{kWy} \cdot \mathrm{C}_{\mathrm{hu}}$ is the cost of hot utility $\left(500-450^{\circ} \mathrm{C}\right)=115.2 € / \mathrm{kWy}$.

A single period comparison is made first to illustrate the strength of simulated annealing optimisation method in searching for optimal heat exchanger network configurations.

\subsection{Single period comparison}

In this section the overall cost of the heat exchanger network for a single period, i.e. the start-of-run condition, is opti-

\begin{tabular}{|c|c|c|c|}
\hline Stream & $\begin{array}{l}\text { Inlet } \\
\text { temperature } \\
\left({ }^{\circ} \mathrm{C}\right)\end{array}$ & $\begin{array}{l}\text { Outlet } \\
\text { temperature } \\
\left({ }^{\circ} \mathrm{C}\right)\end{array}$ & $\begin{array}{l}\text { Heat capacity } \\
\text { flow rate } \\
(\mathrm{kW} / \mathrm{K})\end{array}$ \\
\hline H1 & 420 & 60 & 208.5 \\
\hline $\mathrm{H} 2$ & 160 & 40 & 175.2 \\
\hline H3 & 360 & 60 & 134.1 \\
\hline C1 & 72 & 373 & 211.1 \\
\hline C2 & 62 & 210 & 140.5 \\
\hline C3 & 220 & 370 & 174.5 \\
\hline C4 & 249 & 286 & 271.2 \\
\hline
\end{tabular}

Table 7 - Results from MINLP-NLP model of Verheyen and Zhang (2006) for single period heat exchanger network design.

\begin{tabular}{ll}
$H U_{\text {up }}(\mathrm{kW})$ & Total annualised cost $(€ / \mathrm{y})$ \\
\hline 50,000 & $6,359,872$ \\
45,000 & $6,304,400$ \\
40,000 & $6,303,146$ \\
35,000 & $6,306,067$ \\
30,000 & $6,303,146$ \\
25,000 & $6,363,657$ \\
20,000 & $7,098,245$ \\
16,000 & Infeasible \\
\hline
\end{tabular}

mised using simulated annealing, and is compared with the objective function value from the single period MINLP-NLP model of Verheyen and Zhang (2006). The minimum approach temperature $\left(\Delta \mathrm{T}_{\min }\right)$ used in for this comparison is $25^{\circ} \mathrm{C}$. The MINLP-NLP model is run a number of times with different values of maximum hot utility $\left(H U_{\text {up }}\right)$ available as this can influence the solving path and can lead the search towards a set of different local minima. Table 7 shows the objective function values for the specified minimum approach temperature with various upper bounds for hot utility. The objective function is the total annualised cost (TAC) consisting of the capital cost (fixed and area costs for heat exchangers) and energy cost (hot and cold utility costs).

The heat exchanger network with lowest overall cost obtained using the simultaneous single period MINLP-NLP model of Verheyen and Zhang (2006) is shown in Fig. 7. The total annualised cost of this network is $6.3 \mathrm{MM} € / \mathrm{y}$.

The simulated annealing parameters used to obtain heat exchanger network for single period operation with minimum total annualised cost are shown in Table 8.

The total annualised cost obtained by simulated annealing for the single period heat exchanger network with the same minimum approach temperature is $6.13 \mathrm{MM} € / \mathrm{y}$, corresponding to a $2.7 \%(0.17 \mathrm{MM} € / \mathrm{y})$ reduction to the minimum value of the objective function achieved from all of the various implementations of MINLP-NLP optimisation approach of Verheyen and Zhang (2006). The reduction in total annualised cost compared to the average value of the various implementations of the approach of Verheyen and Zhang (2006) is $4.6 \%$, indicating, in overall, a better performance of the proposed approach for the design of single period heat exchanger networks. The heat exchanger network configuration obtained by simulated annealing is presented in Fig. 8.

The annealing history, i.e. the progress of the optimisation run of $5 \mathrm{~min}$ and $45 \mathrm{~s}$ (Pentium ${ }^{\circledR} 4 \mathrm{CPU} 3.00 \mathrm{GHz}$ processor and 512 MB RAM), for the design of heat exchanger network for single period operation using simulated annealing is shown in Fig. 9. The annealing history in Fig. 9 shows the objective function, i.e. the total annualised cost of the heat exchanger network against the inverse logarithm of annealing temperature.

Table 8 - Simulated annealing parameters used for optimisation of heat exchanger networks in this work.

Initial annealing "temperature" $\quad 0.10 \mathrm{E}+10$ Final annealing "temperature" $\quad 0.10 \mathrm{E}-07$

$\begin{array}{ll}\text { Cooling parameter } & 0.50 \mathrm{E}-02\end{array}$

Markov chain length $\quad 50$

Acceptance criterion Metropolis 


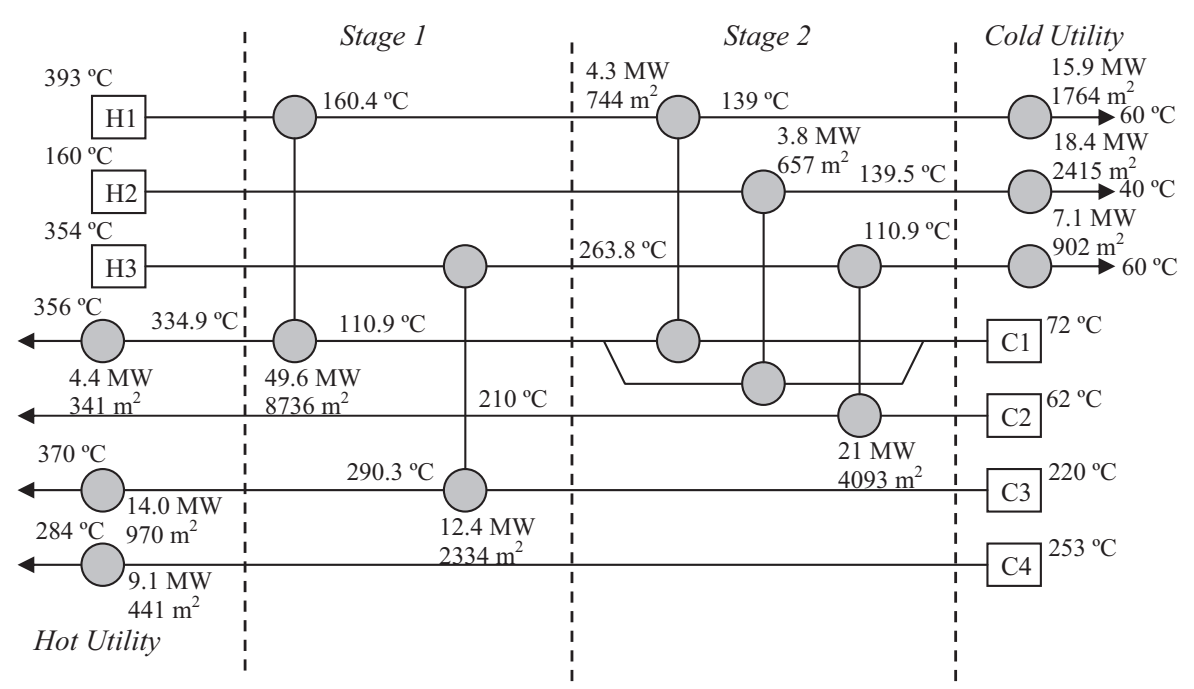

Fig. 7 - Heat exchanger network for single period operation using the MINLP-NLP model of Verheyen and Zhang (2006).

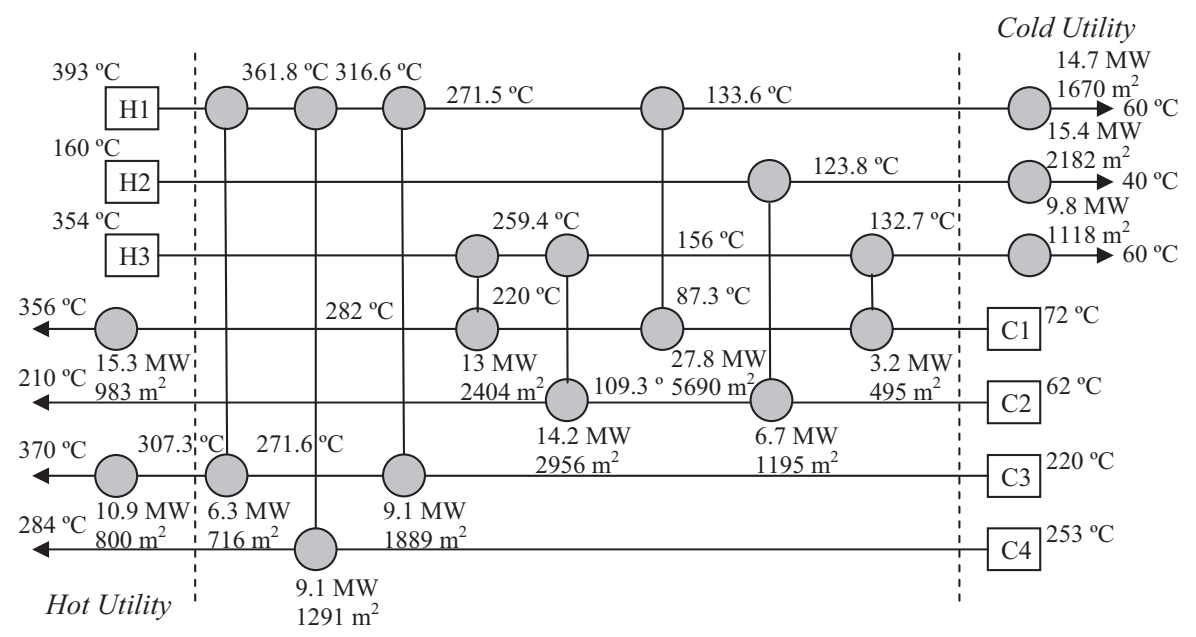

Fig. 8 - Heat exchanger network for single period operation obtained using simulated annealing.

It is evident from the comparison of the results for single period design using simulated annealing and deterministic optimisation approach that simulated annealing can be a more robust optimisation approach for heat exchanger network design and optimisation and can provide designs with bigger savings compared to those of deterministic optimisation strategies.

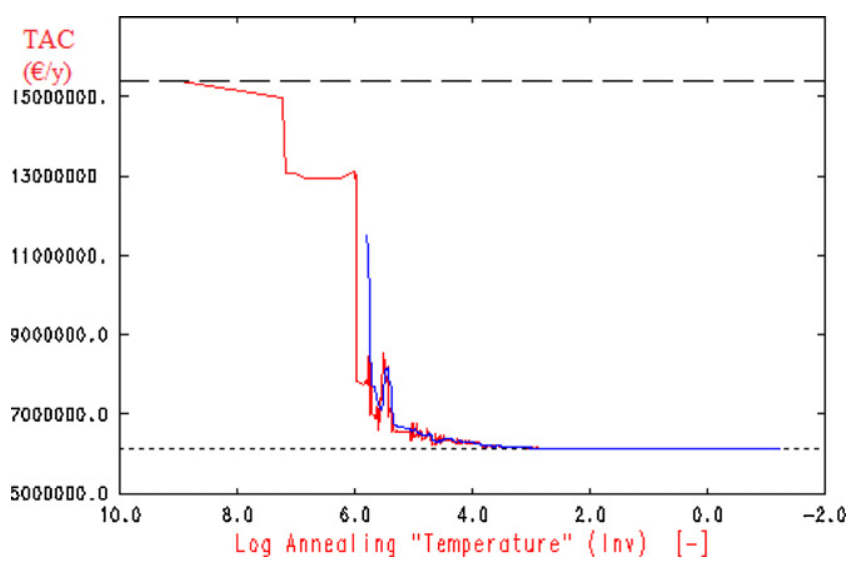

Fig. 9 - Annealing history for single period HEN using simulated annealing.

\subsection{Multi-period comparison}

In this section the results obtained using the proposed methodology for the design of multi-period heat exchanger networks are compared with those obtained by the multiperiod MINLP-NLP approach of Verheyen and Zhang (2006). The objective is to design a heat exchanger network that remains operable in all the three specified periods of operation and has the minimum total annualised cost given by Eq. (19).

The objective function for multi-period heat exchanger network is the total annualised cost, i.e. the sum of capital costs (heat exchanger unit costs and maximum area costs) and operating costs (hot and cold utility costs) for all the periods of operation under consideration. Table 9 shows the results obtained using the simultaneous multi-period model for a minimum approach temperature $\left(\Delta \mathrm{T}_{\min }\right)=25^{\circ} \mathrm{C}$ with various upper bounds for hot utility ( $H U_{u p}$ ).

It can be observed from Table 9 that the simultaneous multi-period model is strongly influenced by the constraints applied and may lead to different solutions or even infeasibility. The multi-period heat exchanger network with lowest total annualised cost is chosen from this set for testing the strengths and weaknesses of the proposed methodology for multi-period heat exchanger network design. The multiperiod heat exchanger network with lowest total annualised 


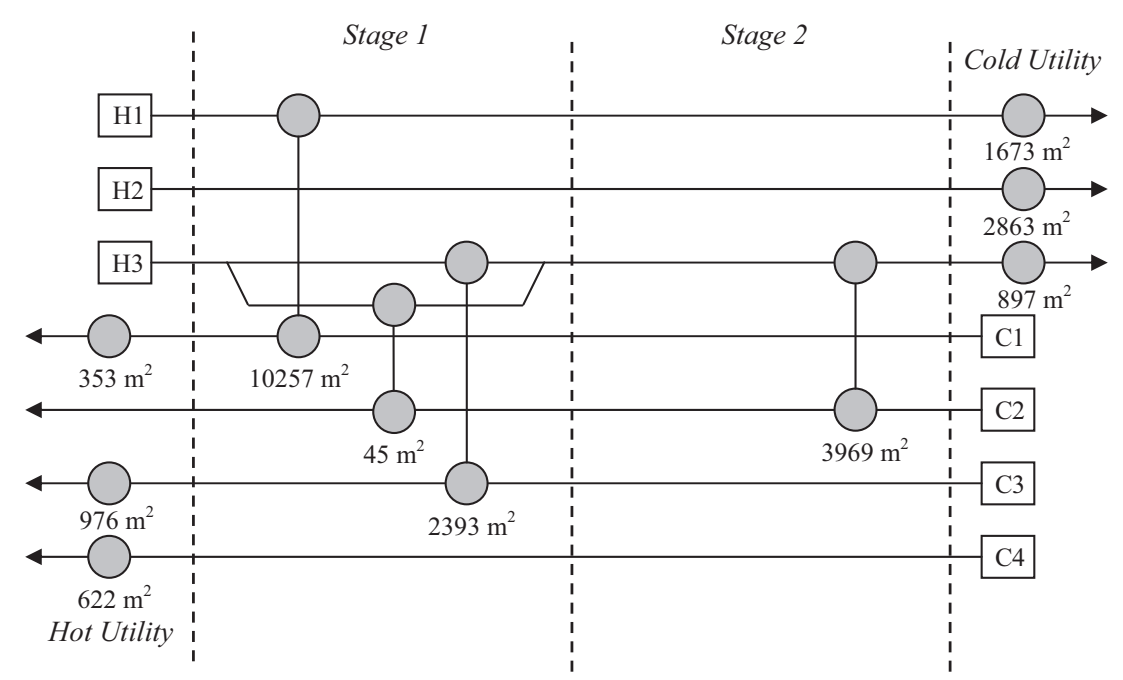

Fig. 10 - Heat exchanger network for multi-period operation using the MINLP-NLP model of Verheyen and Zhang (2006).

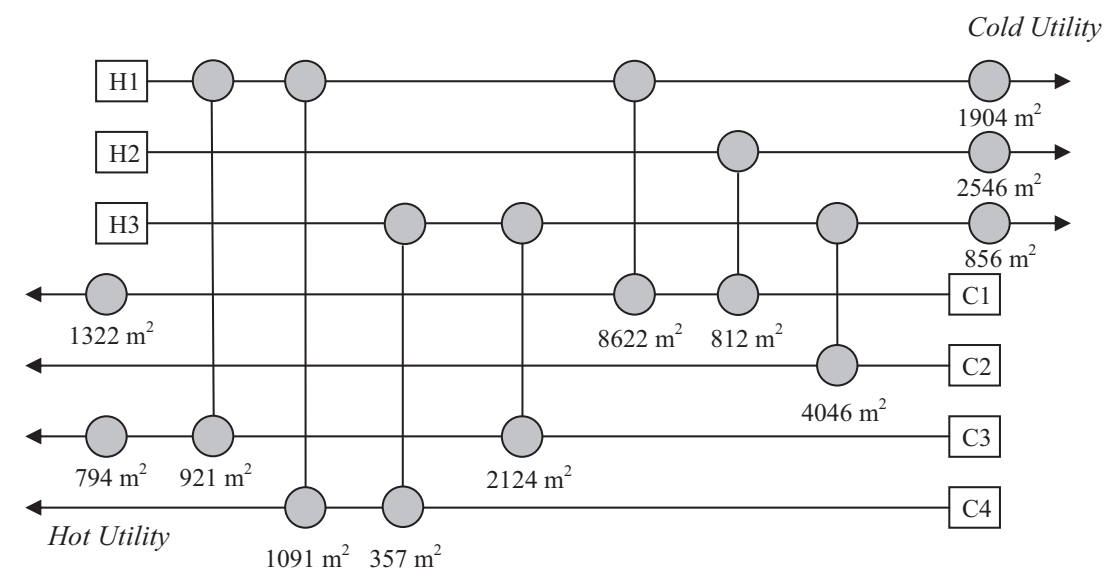

Fig. 11 - Heat exchanger network for multi-period operation by simulated annealing.

cost is shown in Fig. 10. The total annualised cost of this design is $6.41 \mathrm{MM} € / \mathrm{y}$.

Fig. 10 shows the maximum area of each heat exchanger based on the three operating periods under consideration.

The simulated annealing parameters used to obtain heat exchanger network for multi-period operation with minimum total annualised cost are the same as those used for single period design, as already presented in Table 8 . The total annualised cost for multi-period heat exchanger network obtained using the proposed methodology for the same minimum approach temperature is $6.34 \mathrm{MM} € / \mathrm{y}$ and corresponds to a reduction of $1 \%(65,000 € / y)$ to the minimum value of the objective function obtained using multi-period MINLP-NLP model. The reduction in total annualised cost compared to the average value of the various implementations of the approach

\section{Table 9 - Results from simultaneous multi-period} approach by Verheyen and Zhang (2006).

\begin{tabular}{ll}
$H U_{\text {up }}(\mathrm{kW})$ & TAC $(€ / \mathrm{y})$ \\
\hline 50,000 & $6,416,403$ \\
45,000 & $7,591,377$ \\
40,000 & $6,431,203$ \\
35,000 & $6,410,355$ \\
30,000 & $6,431,203$ \\
25,000 & $6,641,023$ \\
20,000 & Infeasible \\
18,000 & Infeasible
\end{tabular}

of Verheyen and Zhang (2006) is $4.6 \%$, indicating, in overall, a better performance of the proposed approach for the design of multi-period heat exchanger networks. The heat exchanger network configuration for multi-period operation obtained by simulated annealing is presented in Fig. 11. Fig. 11 shows the maximum area of each match from all the three operating periods under consideration.

An interesting feature that can be observed here is that the overall costs for multi-period designs are higher than the single period designs. The reason behind this increase in overall costs is that multi-period designs provide the flexibility to remain operable under different operating conditions at the expense of additional costs related to heat exchanger area.

\section{Conclusions}

A new methodology for design of multi-period heat exchanger networks using the simulated annealing algorithm has been developed in this work. The new approach promises to obtain heat exchanger network designs that are flexible and can operate feasibly in multiple modes of operation. A multi-period model for the simulation of overall heat exchanger network is also presented. The main strengths of this approach are that the simulated annealing algorithm does not rely on simplified superstructure explicitly and can explore a greater search area accounting for multiple time intervals. 
It may be observed from the case study that there is no stream splitting in the heat exchanger networks designed using the proposed approach. Stream splitting offers an additional degree of freedom during optimisation and the proposed multi-period model incorporates stream splitters and mixers. However, in order to obtain simple and practicable network configurations, stream splitting was not employed in the case study presented. It is also worth mentioning here that one of the drawbacks of simulated annealing is the higher computation time required to search for solutions in the vicinity of global optimum (Ahmad et al., 2011). This issue would need to be addressed in order to further improve the utility of the proposed approach for design of multi-period heat exchanger networks.

The previously developed simultaneous multi-period models are strongly influenced by the constraints applied and may lead to different solutions or even infeasibility. The proposed approach addresses these limitations, utilizing stochastic optimisation algorithm. The approach presented in this paper is not subject to decomposition of the design problem and therefore takes into account the trade-offs between energy costs, number of heat exchanger units and area costs simultaneously. The proposed approach may help develop cost-effective heat exchanger network designs for both single period and multi-period operation.

\section{Acknowledgement}

Ahmad, M.I. would like to acknowledge the efforts of Prof. Hisham El-Dessouky for promoting research oriented culture at the Department of Chemical Engineering, UET Peshawar.

\section{References}

Aaltola, J., 2002. Simultaneous synthesis of flexible heat exchanger network. Appl. Therm. Eng. 22 (8), 907-918.

Ahmad, M.I., Zhang, N., Jobson, M., 2011. Integrated design of diesel hydrotreating processes. Chem. Eng. Res. Des. 89 (7), 1025-1036.

Androulakis, I.P., Venkatasubramanian, V., 1991. A genetic algorithmic framework for process design and optimization. Comput. Chem. Eng. 15 (4), 217-228.

Athier, G., Floquet, P., Pibouleau, L., Domenech, S., 1996. Optimization of heat exchanger networks by coupled simulated annealing and NLP procedures. Comput. Chem. Eng. 20, S13-S18.

Athier, G., Floquet, P., Pibouleau, L., Domenech, S., 1997. Process optimization by simulated annealing and NLP procedures. Application to heat exchanger network synthesis. Comput. Chem. Eng. 21, S475-S480.

Bjork, K.M., Westerlund, T.M., 2002. Global optimisation of heat exchanger network synthesis problems with and without the isothermal mixing assumption. Comput. Chem. Eng. 26 (11), 1581-1593.

Cerda, J., Galli, M.R., 1990. Synthesis of flexible heat exchanger networks-II. Nonconvex networks with large temperature variations. Comput. Chem. Eng. 14, 213-225.

Cerda, J., Westenberg, A.W., Mason, D., Linhoff, B., 1983. Minimum utility usage in heat exchanger network synthesis. A transportation problem. Chem. Eng. Sci. 38 (3), 373-387.

Cerda, J., Galli, M.R., Camussi, N., Isla, M.A., 1990. Synthesis of flexible heat exchanger networks-I. Convex networks. Comput. Chem. Eng. 14, 197-211.

Chen, L., 2008. Heat-integrated crude oil distillation system design. PhD Thesis. The University of Manchester, UK.

Ciric, A.R., Floudas, C.A., 1991. Heat exchanger network synthesis without decomposition. Comput. Chem. Eng. 15 (6), 385-396.
Dolan, W.B., Cummings, P.T., Le Van, M.D., 1990. Algorithmic efficiency of simulated annealing for heat-exchanger network design. Comput. Chem. Eng. 14 (10), 1039-1050.

Floudas, C.A., Grossmann, I.E., 1986. Synthesis of flexible heat-exchanger networks for multiperiod operation. Comput. Chem. Eng. 10 (2), 153-168.

Galli, M.R., Cerda, J., 1991. Synthesis of flexible heat exchanger networks-III. Temperature and flowrate variations. Comput. Chem. Eng. 15, 7-24.

Hohmann, E.C., 1971. Optimum networks for heat exchange. PhD Thesis. University of Southern California.

Kirkpatrick, S., Gellat, C.D., Vecchi, M.P., 1983. Optimisation by simulated annealing. Science 220 (4598), 671-680.

Lewin, D.R., 1998. A generalized method for hen synthesis using stochastic optimization - II. The synthesis of cost-optimal networks. Comput. Chem. Eng. 22 (10), 1387-1405.

Lewin, D.R., Wang, H., Shalev, O., 1998. A generalized method for hen synthesis using stochastic optimization-I: General framework and MER optimal synthesis. Comput. Chem. Eng. 22 (10), 1503-1513.

Lin, B., Miller, D.C., 2004. Solving heat exchanger network synthesis problems with tabu search. Comput. Chem. Eng. 28 (8), 1451-1464.

Linnhoff, B., Flower, J.R., 1978. Synthesis of heat-exchanger networks. 1. Systematic generation of energy optimal networks. AIChE J. 24 (4), 633-642.

Linnhoff, B., Hindmarsh, E., 1983. The pinch design method for heat-exchanger networks. Chem. Eng. Sci. 38 (5), 745-763.

Ma, X., Yao, P., Luo, X., Wilfried, R., 2007. Synthesis of flexible multi-stream heat exchanger networks based on stream pseudo-temperature with genetic/simulated annealing algorithms. J. Chin. Inst. Chem. Eng. 38, 321-331.

Ma, X., Yao, P., Luo, X., Wilfried, R., 2008. Synthesis of multi-stream heat exchanger network for multi-period operation with genetic/simulated annealing algorithms. Appl. Therm. Eng. 28, 809-823.

Masso, A.H., Rudd, D.F., 1969. Synthesis of system designs. 2 Heuristic structuring. AIChE J. 15 (1), 10.

Metropolis, N., Rosenbluth, A.W., Rosenbluth, M.N., Teller, A.H., Teller, E., 1953. Equation of state calculations by fast computing machines. J. Chem. Phys. 21 (6), 1087-1091.

Nielsen, J.S., Briones, V., Kokossis, A.C., 1994. An integrated framework for the optimal design of heat recovery systems. In: AIChE Annual Meeting, San Francisco.

Nishida, N., Stephanopoulos, G., Westerberg, A.W., 1981. A review of process synthesis. AIChE J. 27 (3), 321-351.

Papoulias, S.A., Grossmann, I.E., 1983. A structural optimization approach in process synthesis. 2. Heat-recovery networks. Comput. Chem. Eng. 7 (6), 707-721.

Ravagnani, M.A.S.S., Silva, A.P., Arroyo, P.A., Constantino, A.A., 2005. Heat exchanger network synthesis and optimisation using genetic algorithm. Appl. Therm. Eng. 25 (7), 1003-1017.

Rodriguez, C.A., 2005. Fouling mitigation strategies for heat exchanger networks. PhD Thesis. The University of Manchester, UK.

Smith, R., 2005. Chemical Process Design and Integration, Second ed. Wiley, New York.

Swaney, R.E., Grossmann, I.E., 1985a. An index for operational flexibility in chemical process design, part I: formulation and theory. AIChE J. 31 (4), 621-630.

Swaney, R.E., Grossmann, I.E., 1985b. An index for operational flexibility in chemical process design, part II: computational algorithms. AIChE J. 31 (4), 631-641.

Tantimuratha, L., Asteris, G., Antonopoulos, D.K., Kokossis, A.C., 2001. A conceptual programming approach for the design of flexible heat exchanger networks. Comput. Chem. Eng. 25, 887-892.

Verheyen, W., 2005. Design of flexible heat exchanger networks for multi-period operation. M.Sc. Dissertation. The University of Manchester, UK.

Verheyen, W., Zhang, N., 2006. Design of flexible heat exchanger network for multi-period operation. Chem. Eng. Sci. 61, 7730-7753. 
Yee, T.F., Grossmann, I.E., 1991. Simultaneous-optimization models for heat integration. 2. Heat-exchanger network synthesis. Comput. Chem. Eng. 14 (10), 1165-1184.

Yee, T.F., Grossmann, I.E., Kravanja, Z., 1990.

Simultaneous-optimization models for heat integration. 1. Area and energy targeting and modelling of multi-stream exchangers. Comput. Chem. Eng. 14 (10), 1151-1164.

Yu, H., 2000. A combined genetic algorithm/simulated annealing algorithm for large scale system energy integration. Comput. Chem. Eng. 24 (8), 2023-2035.
Zhu, X.X., 1995. Automated synthesis of hens using block decomposition and heuristic rules. Comput. Chem. Eng. 19, S155-S160.

Zhu, X.X., 1997. Automated design method for heat exchanger network using block decomposition and heuristic rules. Comput. Chem. Eng. 21 (10), 1095-1104.

Zhu, X.X., O'Neil, B.K., Roach, J.R., Wood, R.M., 1995. Area targeting methods for the direct synthesis of heat exchanger networks with unequal film coefficients. Comput. Chem. Eng. 19 (2), 223-239. 